\title{
Küreselleşmenin Tetikçisi: Medya
}

\author{
DOI: 10.26466/opus.647114
}

*

\author{
Volkan Yavuz * \\ * Öğr. Gör. Dr., Ankara Hacı Bayram Veli Üniversitesi Polatlı Sosyal Bilimler Meslek Yüksekokulu, \\ Ankara/Türkiye
}

E-Posta: v.yavuz@hbv.edu.tr

ORCID: 0000-0001-8617-2994

\section{Öz}

Küreselleşme, ekonomik ve kültürel alanda kendini gösteren ve insan yaşamının merkezinde olması nedeniyle büyük etkiler yaratan bir kavramdır. Küreselleşmenin insanların çă̆gaşlı̆̆a daha kolay ulaştırabileceği fikrini savunanlar ile küreselleşmenin insanları köleleştirdiğ̈i fikrini savunanların arasında yıllardır büyük tartışmalar yaşanmaktadır. Bu kavramla ilgilenen veya ilgilenmeyen herkes küreselleşmenin etkilerini yaşamaktadır. Küreselleşme, topluma hissettirdiğgi bakımından büyük bir organizasyon olarak görülmekte ama somut olarak bu organizasyonu kimse tanımlayamamaktadir. Küreselleşmenin hizmetkarları toplum içinde herkes olabilir. Küreselleşme aynı zamanda bir yaşam kültürü̈ olarak karşımıza çıkmaktadır. Insanlar arasında iletişimin kolaylaşması ve kitle iletişiminin genişlemesi, küreselleşmenin yaygınlaşması için önemli bir zemin oluşturmaktadır. İnsanlar arasında iletişimin kısıtlı olduğu dönemlerde küreselleşmenin ortaya çıkmamış olması da yaygıılaşmak için zemin bulamamış olmasından kaynaklanmış olabilir. Bu durumda medyanın küreselleşmenin yaygınlaşmasında büyük öneme sahip olduğu söylenebilir. Bu çalışmada, küreselleşme kavramı çeşitli boyutlarıyla ele alınmış ve küreselleşmenin yaygınlaşmasında kullandığı en büyük enstrüman olan medya ile ilişkisi incelenmiştir. Medyanın, küreselleşmenin bir ürünü mü yoksa küreselleşmenin lokomotifi mi olduğu tartışmalarına yer verilmiştir. Bu çalışma, küreselleşmenin insanların hayatına medya aracılığılyla tesir ettiği düşüncesiyle, reklam ve medya araçları bağlamında tüketim kültürünün tasarlandığı görüşü ile değerlendirme amaçlı bir araştırmayı içermektedir.

Anahtar Kelimeler: Küreselleşme, Medya, Küresel Ekonomi, 


\title{
Triggers Of Globalization: Media
}

\begin{abstract}
Globalization is a concept that manifests itself in the economic and cultural spheres and has great impact on the center of human life. For years, there has been great controversy between those who advocate the idea that globalization can lead people to modernity more easily and those who argue that globalization enslaves people. Anyone interested in this concept or not is experiencing the effects of globalization. Globalization is seen as a big organization in terms of making it feel to the society, but no one can define it concretely. Servants of globalization can be anyone in society. Globalization also appears as a culture of life. Facilitation of communication between people and the expansion of mass communication provides an important basis for the spread of globalization. The fact that globalization did not emerge during periods of limited communication between people may have been due to the fact that it could not find a basis for spreading. In this case, it can be said that the media is of great importance in the spread of globalization. In this study, the concept of globalization is discussed with its various dimensions and its relation with the media, which is the largest instrument used in the spread of globalization, is examined. It is discussed that the media is a product of globalization or the locomotive of globalization. This study includes a research for the purpose of evaluation with the idea that globalization affects people's life through the media, the view that the consumer culture is designed in the context of advertising and media tools.
\end{abstract}

Keywords: Globalization, Media, Global Economy 


\section{Giriş}

İlk olarak yirminci yüzyılın ortalarında ortaya çıkan küreselleşme kavramı, toplumların birbirleriyle dayanışması fikrini taşımaktadır. Ekonomik ve kültürel anlamda dayanışmayı içeren bu kavram daha sonra büyük bir rekabet ve büyükler arasında dayanışma gibi durumlara sahne olmuştur. Küreselleşme kavramının öncülerinden Muray Rothbard ve David Friedman gibi isimler aynı zamanda liberalleşmenin de savunucularıdırlar (Held ve McGrew, 2008). Tarihsel süreçte devletlerin ekonomi düzenlerine bakıldığında genellikle devleti yönetenlerin piyasaya doğrudan müdahalesi olduğu ve hatta bazı yönetimlerde bütün sektörleri devletin tekelinde bulundurduğunu görmekteyiz. 20. yüzyılda daha da önem kazanan liberal anlayış, aynı zamanda küreselleşme kavramının da omurgasını oluşturmaktadır.

Küreselleşme; uluslararasılaşma sürecinin tamamlanıp, bölgesel olmayan üretim dokularının üretim ve tüketiminin dünya ölçeğinde planladığı, serbest rekabet ve piyasa düzeninin uluslarüstü kuruluşlar tarafından denetlendiği, kuralların uluslarüstü anlayışla çalıştığı bir sistemdir (Kutlu, 2008, s.32).

Küreselleşme kavramının ortaya çıktığı süreç ile şimdiki arasında büyük değişiklikler olmuştur. Bu kavramın ortaya atıldığı yıllardan bugüne kadar, teknolojide ve ekonomi piyasalarında büyük gelişmeler yaşanmıştır. Bu süreçte küçük sermayeli firmalardan bazıları büyük işletmeler haline gelmiş, bazı küçük firmalar birleşerek büyümüş, bazı sektörler tekel firmaların eline geçmiş, büyük balığın küçük balığı yediği bir ekonomik düzen oluşmuştur. Bilim ve teknolojideki gelişmeler ve özellikle iletişim ağlarındaki büyük yeniliklerle birlikte dünya küçülmüş, iletişim kolaylaşmış ve 1960'larda Kanadalı iletişimci Marshall McLuhan'ın söylemiş olduğu "Küresel Köy" (Global Village) kavramı belki de gerçek anlamını bulmuştur.

Büyük sermayeleri elinde bulunduran, piyasaları yönlendiren sermayedarlar kendi hegemonyalarının devamı için bazı silahlar kullanmaları gerekmiştir. Onların insanları hedef kitle veya hedef tüketici olarak görmeleri nedeniyle hayatlarına en kolay girebilecekleri yol ise medya araçlarından geçmektedir. İnsanları bilgilendirme, eğlendirme ve eğitme gibi misyonları olan medya araçları, özellikle küreselleşme kavramının hayatımızda daha büyük bir yere sahip olduğu son yıllarda küreselleşmenin tetikçiliğini yapmaktadır. 
Küreselleşme kavramını biraz idrak ettikten sonra hayatımızda ne kadar belirleyici bir rol oynadığını hissetmek çok kolaydır. Oldukça farklı argümanları kullanarak bunu gerçekleştiren küreselleşmenin en önemli silahının medya olduğu düşüncesiyle bu araştırma yapılmıştır. Araştırma kapsamında sınırlılıklar, medya araçlarının yapısı, medya araçlarında yayınlanan reklamlar ve bu yolla oluşturulan tüketim kültürü ile belirlenmiştir.

Reklamcllık sektörünün son yıllarda büyümesi, medya araçlarının niteliklerinin artması ile doğru orantılı olmuştur. Bu çalışma kapsamında reklamcılık sektörünün durumu, Türkiye'deki reklam yatırımları bağlamında ele alınmıştır.

Çalışmanın sonucunda Türkiye'deki reklam yatırımları ve reklam mecralarının sektördeki payları belirtilerek tüketim kültürünün reklam sektörü ile ilişkisi üzerinde durulmuştur. Değerlendirme amaçlı bu çalışmada nitel analizlerin yanında nicel görüşler de belirtilmiş ve sonuç bölümünde küreselleşmenin bir reklam mecrası olarak kullanılan medya ile ilişkisi üzerine değerlendirmeler yapılmıştır. Medyanın bilgilendiririci ve eğlendirici bir platform olmasının yanında, faaliyetlerinin yürütülmesi amacıyla alınan reklamların toplumu nasıl etkilediği üzerinde durulmuştur.

\section{Küreselleşme Kavramı}

Literatürde küreselleşmeyle ilgili birçok tanıma rastlamaktayız. Bu tanımların çok sayıda olmasının nedeni küreselleşmenin sürekli değişen yönlerinin bulunması ve etki ettiği mecraların değişmesidir. Küreselleşmenin bu kadar çok tanımı varken hepsinin üzerinde mutabık kaldığı konu; küreselleşmenin çok boyutlu olmasıdır. Kavramın daha çok ekonomik boyutu ön planda olsa da, aynı zamanda siyasal, toplumsal, kültürel ve çevreyle ilgili bir olgu olduğunu ve teknolojik/ideolojik boyutlara sahip bir süreci kapsadığını da söylemek mümkündür (Giddens, 1998: 67; Setzer, 1997: 11).

Küreselleşmenin ortaya çıkmasında oldukça farklı dinamikler bulunmaktadır. İletişim teknolojilerinin gelişmesinin dünyayı daha küçük hale getirdiği kabul edilirken bu süreçte ekonomik beklentiler de değişmiştir. Tüketimin küreselleşmesine dayanan bu durum, küresel üretimin artmasına ve ekonomik kaynakların da dengesiz şekilde dağıldığı bir dünyaya doğru yolculuğa başlamıştır. Küresel ekonominin şekillenmesinde devletler doğrudan rol almış ve küreselleşen dünyada söz sahibi olmak için kendi 
toprakları dışında büyük yatırımlar yapmıştır. Küresel ekonominin şekillenmeye başlaması ve iletişim ağlarındaki gelişmeler ile birlikte küreselleşmenin hukuki açıdan zemini de oluşturulmuştur. Küreselleşmenin teknolojik açıdan insanlara sunduğu yenilikler artık bu hukuki zemin sayesinde tüm dünyaya kısa sürede ulaşabilmiştir.

George Modelski, "küreselleşme dünyanın büyük medeniyetleri arasındaki artan bağlantının tarihidir" der. Küreselleşme kavramı en eski medeniyetler arsında düzensiz aralıklarla ortaya çıkan karşılaşmalara kadar uzanan, uzun vadeli tarihsel bir süreçtir. Modelski'ye göre küreselleşme, uluslar, medeniyetler ve siyasal topluluklar arasındaki genel dayanışmanın genişlemesinin ve derinleşmesinin tarihsel sürecini kapsayan bir kavramdır (Held ve McGrew, 2008, s.71). Küreselleşmenin fikir mimarları Muray Rohtbard ve David Friedman gibi liberal düşünürlerdir. Bu düşünürler 1970'li yıllardan itibaren 'piyasaların serbestliği ilkesi'ni çalışmalarının merkezine koymuşlar böylece 'bırakınız yapsınlar' şeklindeki liberal ideolojinin geçerliliğini kanıtlamaya çalışmışlardır. Söz konusu liberal söylem kaynağını, Ludwig von Mises ve Friedrich von Hayek'in temsil ettiği Macar Ekonomi Okulu düşünürlerinden almaktadır (Tutal, 2006, s.22-23).

Liberal düşüncenin yaygınlaşması sonrasında ortaya kendiliğinden çımış gibi görünen küreselleşme, belki de büyük bir organizasyonun kapsamlı bir senaryosuydu. Bu ortaya çıkış sürecinde bir grup araştırmacı küreselleşmenin tanımını yapmışlar ve kapsamını belirlemeye çalışmışlardır. $\mathrm{Bu}$ araştırmacılara küreselleşmenin mimarları gözüyle bakılsa da belki de sadece gelişen bir süreci anlamlandırmaya çalışmaktaydılar.

"İnsanların ve Metaların dünyanın bir noktasından çok uzaktaki bir başka noktasına ulaşım süreci giderek azalmakta, mekanın oluşturduğu engeller aşılmakta ve dünya küçülmektedir" vurgusunda bulunan Perry Anderson küreselleşmeyi, "aynı ya da benzer süreçlerin, eşitsiz biçimde de olsa ulusüstü ölçeklerde kendisini gösterme eğilimi olarak" tanımlamaktadır (Aktaran Boratav, 2000, s.18).

Küreselleşmenin ortaya çıkması ve kısa sürede yaygınlaşması, teknolojik ve ekonomik gelişmelere bağlı olduğu için sürecin toplumu şekillendirmesi ile küreselleşmenin etkileri hissedilmeye başlamıştır. İletişim ağlarının gelişmediği dönemlerde kültürel geçişlerin çok keskin olduğu düşünülecek olursa ilk olarak küreselleşme kültürlerin etkileşimini sağlamıştır. Günü- 
müzde bile kültürel öğelerin paylaşılarak diğer toplumlar tarafından tanınması, benimsenmesi ve kullanılması oldukça yaygın görülen bir durumdur. $\mathrm{Bu}$ durumun sonucu olarak dünya üzerinde sosyal açıdan birbirine oldukça benzeyen toplumlar oluşmaya başlamıştır. Katı kültürel öğelerin yaşama şansı bulamadığı günümüzde yumuşak kültürel öğeler de geniş topluluklar tarafından hızlı bir şekilde benimsenebilmektedir.

Küreselleşmenin başlangıcının ikinci dünya savaşı sonrasında New England'taki Bretton Woods'ta toplanan bir ekonomi konferansına kadar uzandığı söylenebilir. Konferansa katılanlar, uluslararası ticareti geliştirmenin yanı sıra, uluslararası ekonomik faaliyetler konusunda da bağlayı $\mathrm{ku}-$ ralları belirlemişlerdir (Steger, 2006, s.62). Ayrıca bu toplantıda üç yeni örgütün kurulması kararı da alınmıştır. "Uluslararası Para Fonu" (IMF), uluslararası ekonomik sistemin yönetimi için oluşturulmuştur. Daha sonra, "Dünya Bankası" olarak ismi değişecek olan "Uluslararası Yeniden İnşa ve Gelişme Bankası", başlangıçta Avrupa'nın savaş sonrasında yeniden inşası için kredi sağlamaya yönelik tasarlanmıştır. 1950'lerde ise bankanın amacı, gelişmekte olan ülkelerdeki çeşitli sanayi projelerine fon sağlayacak şekilde genişletilmiştir. Son olarak, 1947'de çok taraflı ticaret anlaşmalarını yapmak ve uygulamakla görevli küresel bir ticaret örgütü olarak "GATT" (Gümrük Tarifeleri ve Ticaret Genel Anlaşması) oluşturulmuştur. 1995'te GATT'ın yerine geçmek üzere, Dünya Ticaret Örgütü" (DTÖ) kurulmuştur (Steger, 2006, s.63).

Batıda doğan küreselleşme kavramı böylelikle kendisine sağlam bir ekonomik temel oluşturduktan sonra daha geniş alanlara yayılmaya başlamıştır. Batı'da gerçekleşen bu ekonomik işbirlikleri ve anlaşmalar, büyük bir özel sektörün doğmasını da hızlandırmıştır. Liberal ekonomik düzenin getirdiği avantajlarla endüstrileşme hızlanmış, büyük sermayeler oluşmuştur. Birçok sektörde tekelleşmenin başlangıcı da bu döneme rastlamaktadır.

Ulaşım ve iletişim araçları sayesinde dünyadaki coğrafi mesafeler zaman ve mekan anlaminda küçülmüştür. Böylece, insanlar, uluslar ve kültürler arasındaki ilişkiler dünya ölçeğinde giderek yoğunlaşmıştır. Marshall McLuhan'ın dünyanın "küresel köy"'e dönüştüğü söylemi çerçevesinde, insanlar kıtalararası toplumlarla bile sosyal, ekonomik ve kültürel ilişki kurabilir hale gelmiştir. Bu anlamda, günümüzde iletişim teknolojilerindeki ge- 
lişmelere bağlı olarak "küresel kültür" adıyla gelişmekte olan Batı kültürünün, diğer ulus kültürlerini yoğun bir şekilde etkisi altına aldığından söz edilebilir (Giddens, 1998).

Küreselleşme kavramı her ne kadar ekonomik bir altyapıyla başlasa bile, bu altyapıyı koruyabilmek ve devamlılı̆̆ını sağlayabilmek için insanların gündelik yaşantılarına, kültürlerine ve özel hayatlarına kadar sirayet etmiştir. Kültürel farklılıkların yanı sıra kendisine bir kültür oluşturmayı amaçlayan küreselleşme, insanların yemek alışkanlıkları, giysileri, alışveriş tercihleri gibi konularda genel bir eğilim yaratmaktadır.

Medya da tam burada devreye girmektedir. İnsanların yaşam tarzlarını tüketim kültürüne yönelik şekillendirmeleri kitle iletişim araçlarıyla insanlara empoze edilmektedir. Medya araçları içinde en büyük kitleye ulaşabilen televizyonlarda yayımlanan programlar bu etkiyi göstermektedir. Reklamlarda, dizilerde, yarışma programlarında ve hatta haberlerde bile tüketim toplumunun inşasında istenilen yaşam tarzları insanlara sunulmaktadır.

Son yıllarda toplumu derinden etkileyen yeni medya araçları ise geleneksel medyadan daha fazla olarak küreselleşmenin oldukça önemli bir aracı haline geldiği görülmektedir. Her geçen gün kullanım oranı artan yeni medya araçları, küresel ekonominin gelecek vaat eden enstrümanı olma yolundadır.

\section{Reklamcilık ve Medya}

1970'lerin ilk yarısında başlayan ve uzun süre devam eden yapısal ekonomik kriz ve kesif Japon rekabeti karşında endüstriler ve işletmeler (özellikle otomobil) 1980'li yıllarda hızlı bir yeniden yapılanma ve değişim periyoduna girdiler. İkinci Dünya Savaşı sonrasının egemen üretim paradigması Fordizmi dönüştürmek amacıyla yeni teknoloji ve Japon üretim ve yönetim tekniklerini bünyelerine uyarlamaya başladılar. Bu dönüşüm ve yeniden yapılanma süreci kimi yazarlar tarafından, yaygın bir biçimde post-Fordizm olarak tanımlanan yeni üretim paradigmasının ortaya çıkışı olarak yorumlanmaktadır. Post-Fordizm, kitle üretimine esneklik, kalite ve vasıf gibi yeni özellikler ilâve ederek Fordizm'in kimi boyutlarını tersine çevirmektedir. Bu dönüşümden sonra üretim daha nitelikli hale gelmiş ve etkin pazarlama stratejilerine ihtiyaç duyulmuştur (Parlak, 1999, s.1). 
Bu süreçte Japonya'nın dünya ekonomi piyasasında günümüzdeki konumuna gelinceye kadar yürütmüş olduğu ekonomik politikalarına benzer bir strateji yürüten Çin'de son yıllarda büyük atılımlar yapmıştır. Ucuz ve kalitesiz ürünler ile dünya pazarına giren Çin şirketleri, bir süre sonra kaliteli ürünler de üretmeye başladılar ve bazı sektörlerde tekel konumuna geldiler. Üretim konusunda Honkong'un ABD ile sözleşmesinin bitmesi sonrasında Çin adına büyük gelişmelerin yaşanması tesadüf değildir. ABD'nin üretim alanı olan Honkong sayesinde üretim stratejilerini öğrenen Çin, kısa sürede gerek küresel şirketlere üretim açısından sunduğu imkanlar ile üretim merkezlerini buraya çekmeleri, gerekse kendi üretim stratejilerini doğru şekilde belirleyerek aynı zamanda ihracat odaklı çalışmaları neticesinde bu büyüme kısa sürede gerçekleşmiştir. Her ne kadar ideolojik açıdan küreselleşme kavramı Çin'e ters gibi görünse de Çin, dünyanın ekonomik gücü olma hedefi yolunda küresel argümanları doğru kullanmayı becermiştir.

İnsanların tüketim alışkanlıklarını değiştirerek büyük bir tüketim toplumu yaratmayı başaran küreselleşmenin temelinde büyük ekonomik güçlerin daha da büyüme arzuları gelmektedir. Reklamlar bu değişim en önemli aktörleridir. Reklamların tarihsel gelişim süreci şu şekilde sınıflandırılmaktadır (Leiss vd., 1990'dan aktaran Dağtaş 2003, s.80; Dağtaş, 2009, s.43-44):

1.Dönem (1890-1925) Ürün-Bilgi Formatı Dönemi

2. Dönem (1925-1945): Ürün-İmaj Formatı Dönemi

3. Dönem (1945-1965): Kişiselleştirme Formatı Dönemi

4. Dönem (1965- ... ): Yaşam Tarzı Formatı Dönemi."

İlk dönemde reklamın ilgisi ürün üzerinedir. Bu süreçte reklam içeriklerinde sadece ürünle ilgili bilgiler bulunmaktadır. İkinci dönemde markalar oluşmuş ve bir marka imajı reklamlarla oluşturulmaya çalışılmıştır. Üçüncü dönemde reklamlar psikolojik odaklıdır. Mutluluk, eksiklik ve tatmin gibi duygular ön plandadır. Günümüzde ise reklamlar yaşam tarzı formatıyla bizlere sunulmaktadır.

Günümüzde yaşam, doğal çevreye ek olarak, gelişen teknolojiyle genişleyip güçlenen multidivansiyonel ${ }^{1}$ bir çevrede sürdürülmektedir (Gökçe,

\footnotetext{
${ }^{1}$ Multidivansiyonel; yazı, fotoğraf, ses gibi çok boyutlu yayın tekniklerinin oluşturduğu bir çevre anlamına gelmektedir.
} 
1993, s.83-84). Reklamlar bu çevrede bütün argümanları en etkili şekilde kullanmaktadırlar. Ürünlerin kıyasıya rekabet ettiği piyasalarda bir adım öne geçebilmek için uygun reklam stratejilerine sahip olmak oldukça önemli bir avantaj olmaktadır.

Reklam verenler, reklam mecrası olarak istedikleri kitleye ulaşabilecekleri tüm araçları kullanmaya hazırdır. Reklam verenlerin öncelikli hedefi olabildiğince geniş kitlelere ulaşabilmektir. Medya araçları bu aşamada reklam sektörüne önemli bir zemin oluşturmaktadır.

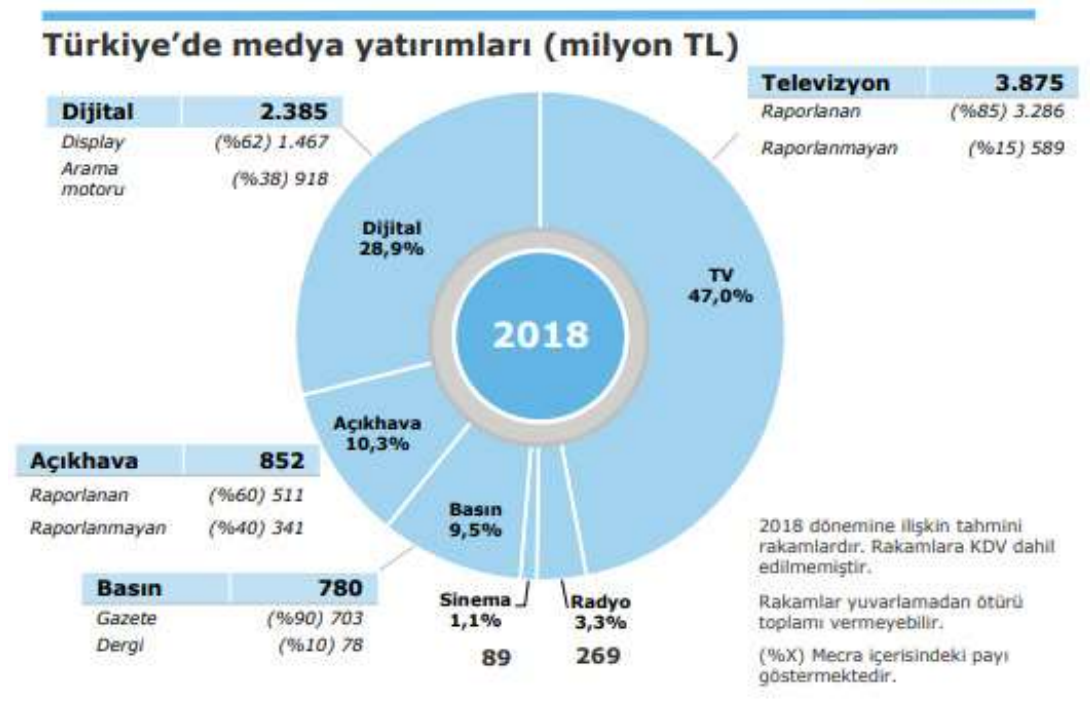

Şekil 1. Reklamcılar Derneği Reklam Yatırımlan Raporu

2018 yılında Reklamcilar Derneği'nin Türkiye'de medya yatırımları konusunda yapmış olduğu çalışmanın grafiği, şekil 1'de gösterilmektedir. Bu rapora göre televizyon reklamları \%47'lik bir oranla en büyük reklam mecrasıdır. Televizyonun hemen ardından dijital reklamlar yaklaşı \%29'luk bir oranla ikinci sırada yer almaktadır. Reklam mecraları içinde Sinema ve Açıhava mecralarının dışında kalan oldukça büyük bir bölüm medya araçlarına aittir. Medyanın reklam mecrası içindeki önemi bu araştırmada da görülmektedir. 
Medya araçları içinde dijital reklamların kapsamında farklı kategoriler bulunmaktadır. Bu kategorilerin içinde de yeni medya araçları başı çekmektedir. İletişim ağlarının gelişmesi ve mobil cihazların yaygınlaşması ile birlikte insanların medya ihtiyaçlarını genellikle yeni medya aracılığıyla giderdikleri görülmektedir. Mobil cihaz kullanımının artmasına paralel olarak ta yeni medya kullanım yaş aralığının büyüdüğü de bir gerçektir.

Reklam stratejileri içinde hedef kitleden hedef bireye doğru uygulamaların oldukça başarılı olduğu bu dönemde veri madenciliği en önemli bilişim iş kollarından birisi haline gelmiştir. Kişiye özel reklam uygulamalarının sadece yeni medya araçlarında yapılabilmesi, etkinliği oldukça yüksek olan bu uygulama için altyapının geliştirildiği bir dönemden geçmekteyiz. Reklam sektörü için gelecek vaat eden bir alan olan yeni medya, aynı zamanda insanların medya ihtiyacını da üst seviyede karşılayan konuma gelmiştir.

\section{Tüketim Kültürü}

Sanayi devrimi sonrasında üretimin artması ve reklamcılık çalışmalarının hızlanmasıyla birlikte özellikle 1980 sonrasına "tüketim toplumu" adı verilmiştir. Tüketim kültürü ve ideolojisinin yaygınlık kazandığı bu dönemin en belirgin özelliğini ise Soner Yağlı (2006, s.6), "gündelik hayatın her alanını kuşatacak şekilde her şeyin tüketime uygun hale getirilmeye çalışılması" olarak tanımlanmaktadır.

Dünya üzerindeki ülkelerde yaşayan toplumlar yaşamsal alanda diğerlerine bağımlı hale gelmişlerdir. Meta üretimi parçalara ayrılıp her bir parçası belirli bir yerde üretilmektedir. En gelişmiş ülkelerde bile insanlar d1şarıdan getirilen mallara bağımlı durumdadır ve yaşam biçimleri hızla değişmektedir. Örneğin araba üreten ülkeler araba yapımında kullanılan parçaların bir kısmını diğer ülkelerden satın almaktadırlar. Üretilen ürünlerin hacim ve hızına bağlı olarak tüketimin hızının da arttırılması zorunlu hale gelmiştir Tüketim hızının arttırılması bir dizi metanın ihtiyaç kategorisi içine sokulması ve bu üretilen meta ve hizmetlerin yeni mekanlarda satışa sunulmasını gerekli kılmıştır. Üretilen ürünlerin tüketiciye ulaşması için de tüketim mekanlarının çoğaltılması yoluna gidilmiştir (İçli 2001, s.166).

Böylelikle, tüketim toplumunda metalar yeni bir sembolik önem tarzı kazanmıştır. Daha da fazlası, giydiğiniz ya da giymediğiniz ne olduğunuzu ya 
da toplumsal haritanın neresinde olduğunuzu tanımlamaya başlamıştır. Bugün sınıflar arası toplumsal geçişkenlik mümkünmüş gibi görünse de, bunun bir bedeli vardır. İnsanların gözünde arzu edilen toplumsal grubun içinde yer alabilmek için gereken geliri kazanına konusunda çok daha fazla baskı vardır. Bunu başarmak için bireyler ve aileler üzerinde çalışma ve harcama baskısı gittikçe yoğunlaşmaktadır. Günümüzde artık insanlar yaşanılanı sürdürebilmek için değil, tüketim mallarını alabilmek için çalışmaktadırlar. Aslında gittikçe artan bir biçimde, tüketim, çalışanlar için satın alma eylemi kadar, satın alma fikrini de güdü haline getirmektedir (Aydoğan, 2009, s.205).

Aynı zamanda tüketim kültürü, tüketicide satın aldığı ürün üzerinden bir kimlik edinme, birey olma ve özgürlüğe sahip olma yanılsamasını yaşatmaktadır. Eşdeyişle, tüketim toplumunun temelinde yer alan "mutluluk" tüketiciye; "mutlu olmak için tüketmelisin, tükettikçe mutlu olmalısın" teması ile verilmekte ve bunun tüketiciler tarafından içselleştirilmesi beklenmektedir. Bu ise, doğrudan reklamlar aracılığıyla gerçekleşmektedir. Gerek hareketli ya da durağan oluşturulan reklamlarda gerekse görsel öğeler ve metinlerde tüketiciye sunulan ürünler belli yaşam biçimlerine ilişkin göstergelerle kodlanmaktadır.

Banu Dağtaş (2003, s.183), reklamın tüketim toplumuna sunduğu değer ve ideolojilerin, ürün veya hizmetin tanitımına baskın olduğu bulgusuna ulaşmıştır. Tüketim toplumunda, boş zamanlar ve yaşam biçimleri reklamın ilgi alanı haline gelmiştir. Eşdeyişle, reklam, üretilenin duyurulmasından çok, tüketimin biçimlendirilmesine girişmektedir. Bunu yaparken bağlantıya geçtiği değerler ve bu değerleri yansıtış biçimi dikkat çekmektedir. Reklamın bilinen bir tanımı da insanların satın alma davranışlarının değiştirilmesine yönelik çalışmalardır. Bu tanımıyla reklamların sosyolojik altyapıları, tüketim kültürünün oluşturulması açısından büyük önem taşımaktadır.

\section{Medya ve Toplum}

Küreselleşmenin temelleri ekonomik alanda atılsa bile sosyokültürel boyutu ile daha etkili hale gelmektedir. Post-fordist dönemde yeni üretim tekniklerinin yaygınlaşması ile büyük bir tüketim toplumu yaratılmış ve hem rekabetin artması hem de üreticiler için tüketicilerin şekillenmesi için reklamlar kullanılmıştır. Bu aşamada medya devreye girerek küreselleşmenin ürünlerini yaygınlaştırabileceği bir argüman olmuştur. 
Gutenberg'in ilk matbaa makinesini icadından sonra bugünkü anlamıyla gazeteler yayımlanmaya başlanmış ve yazılı basın tarihsel süreçte gelişerek geçtiğimiz yüzyılda önemli bir güç ve meslek haline gelmiştir. Elektronik ürünlerin üretilmeye başlanmasıyla yirminci yüzyılın başlarında radyo yayıncılığı başlamış, bu da bir medya aracı olarak kullanılmıştır. Yine bu yüzyılın ortalarına doğru televizyon yayıncılığının başlaması günümüzdeki basın anlayışının en önemli temellerinden birisi olmuştur.

Günümüzde geleneksel medya adını verdiğimiz gazete, radyo ve televizyonlar tarihsel süreçte çok önemli işlevlere sahip olmuşlardır. Yeni medya hayatımıza girene kadar tek yönlü yayın yapan geleneksel medya araçları, siyaset, kültür, ekonomi ve bütün bunları içine alan küreselleşme kavramının şekillenmesinde önemli rol oynamıştır.

Tüketimin artması, reklamların giderek değer kazanması, medya araçlarının geniş kitlelere ulaşmaya başlaması ve toplumu yönlendirme gücünün artmasıyla birlikte kitle iletişim araçları karlı bir yatırım haline gelmişlerdir. Medya araçlarının hem karlı bir yatırım olması hem de sahiplerine kazandıracağı sosyal güç, büyük yatırımcıları buraya çekmiştir.

1970'lerde başlayan ve 1980'li yıllarda iyice belirginleşen süreçler, dünya genelinde yeni sağın ve beraberinde liberal politikaların yükselişini doğurmuştur. Bu süreçte tüm sektörlerde olduğu gibi medya alanında da yoğunlaşma artmıştır. Küçük ve orta büyüklükteki grupların birleşmesi ya da daha büyükler tarafından ele geçirilmesi şeklinde meydana gelen bu olgu, "tekelleri" ortaya çıkarmaktadır (Okuroğlu, 2012, s.30).

Tekelleşme eğilimi, sermaye birikiminin yetersiz olduğu tüm ülkelerde yaygındır. Öte yandan, sanayileşmiş ülkelerde de genellemeye girmemekle birlikte, medya tekelleşmesi sorunu vardır. Bu bağlamda, çoğu Kuzey Amerika kökenli "7 büyük şirket" (Disney, AOL Time, Warner, Sony, News Corparation, Viacom, Vivendi ve Bertelsman) ulusal sınırları aşarak küresel medya tekellerine dönüşmüştür (McChesney ve Schiller, 2003).

Bir yatırımcı için medya sektörüne girmenin avantajları, hükümete ve devlet bürokrasisine yakın olmanın ya da kamuoyuna yönelik oluşturulan etkinin kendisine sağlayacağı yararlardır. Bu çerçevede, medya sektörüne girmeyi çekici kılan başlıca nedenler şu şekilde sıralanabilir (Adaklı, 2001, s.155):

- (A)1.Kitle iletişim araçlarının dördüncü güç olduğu yaklaşımı, 2.Siyasal çevrelerde saygınlık ve baskı, 3 . Toplumsal denetim. 
- (B)1.Diğer sektörlerdeki riski sermayenin güvenceye kavuşturulması, 2.Kredi alımında ve devlet ihalelerinde söz sahibi olma.

- (C)1.Reklam harcaması yapmak yerine, gazete çıkarmak/radyotelevizyon kurmak, 2. Pazarlama, 2.Para ticareti.

1990'lı yıllarda kişisel bilgisayarların hızlı bir şekilde artması, internetin yaygınlaşmasıyla birlikte yeni bir medya aracının temelleri atıldı. Kişisel internet sitelerinin çoğalması, blog adı verilen sitelerin tüm kullanıcılara içerik oluşturma imkanı sağlamasıyla birlikte yeni medyanın şekli de belirmeye başladı. Sosyal medya sitelerinin kullanıc sayısının gün geçtikçe artmasıyla yeni medya kavramı şekillenmeye devam etmektedir.

Sadece masaüstü bilgisayarlarla internete ulaşılabilen günlerden, dizüstü bilgisayarların ucuzlayarak yaygınlaşmasına, kablosuz internet teknolojisinin gelişmesinden akıllı cep telefonlarına ve telefon şebekelerinin internet servis sağlayıcıları olmaları durumuna kadar teknoloji alanındaki gelişmeler sayesinde her geçen gün kullanıcı sayısı artan internet yayıncılığ halen gelişmeye devam etmektedir. Açlan yeni sosyal paylaşım siteleri, mobil telefon uygulamaları ve mevcut sistemlerin sürekli kendini güncellemesiyle bu gelişmenin uzun süre devam edeceği görülmektedir.

Bu gelişme reklam verenlerin de dikkatini çekmektedir. Özellikle televizyon en büyük kitleye ulaşabilen medya aracıdır. Dolayısıyla reklam gelirleri en yüksek kitle iletişim aracıdır. Gazeteler de televizyondan sonra reklam gelirleri sıralamasında ikinci sıradadır. Üçüncü sırada internet reklamcılığı gelse bile gazete tirajlarının gün geçtikçe düşmesi ve internet kullanımının giderek artması nedeniyle ilerleyen süreçte bir yer değişikliği görülebilir (Ratem, 2013).

Son yıllarda televizyon ve internet bağımlılığı konusunda ciddi artışlar meydana gelmiştir. Bu gelişme medyanın insanların hayatının ne kadar içinde olduğunu gözler önüne sermektedir.

\section{Tartışma ve Sonuç}

Son yıllarda gerçekleşen yeniliklerle geçmişi ve şimdiyi farklı analiz ediyor ve isimlendiriyoruz. Yöntemde ve isimde farklılıklar olmasına karşın, ister bilgi çağı, ister elektronik çağ şeklinde tanımlansın; yaşadığımız dönemin "yeni bir çağ" olduğu yönünde uzlaşma bulunmaktadır. İçinde bulunulan 
dönemde, enformasyon akışı insanı kuşatmış ve post-fordist evreyle birlikte yeni üretim ve istihdam biçimleri gündeme gelmiş ve tüketim kültürü kavramından söz edilmeye başlanmıştır (Dağtaş ve Dağtaş, 2009, s.51-52).

İkinci dünya savaşının ardından dünyadaki güç dengelerinin değişmesi, batıda büyük bir endüstrileşme gelişmesinin yaşanması, aynı zamanda doğuda Japonya'nın büyük bir ekonomik güç haline gelmesi ve ABD'nin siyasi gücünün artmasıyla birlikte dünyanın siyasi aktörleri şekillenmeye başlamıştır. Büyük ekonomik güce sahip olan devletler aynı zamanda dünyayı şekillendiren konuma da geçmişlerdir. Büyük ekonomilere sahip ülkelerin dünyayı şekillendirme amaçları; ekonomik ve siyasi çıkarları ile örtüşmektedir.

Küresel güçlerin aynı zamanda ülkelerden bağımsız hareket etmedikleri, aksine küreselleşmenin, birçok gelişmiş ülkenin ortak dışişleri ve ekonomik politikası olduğu görülmektedir. Bu durum sınırların ortadan kalkmasına, devletlerin ve işletmelerin faaliyet alanlarının oldukça geniş coğrafyalara yayılmasına neden olmaktadır.

Ekonomik küreselleşme ile küçük işletmeler birleşmişler veya büyükler tarafından ele geçirilmişlerdir. Sektörlerde belirleyici rol oynayanlar hep büyük aktörler olmuşlardır. İşletmelerin kurulurken devamlılık ve sürekli daha çok kar etme prensipleri gereğince acımasız bir ekonomik düzen oluşmuştur. Küreselleşmenin aktörleri aynı zamanda büyük işletmelerdir. Bu işletmeler değişik iş alanların var oldukları gibi ya doğrudan ya da dolaylı olarak medya alanına da girmişlerdir.

Büyük yatırımcıların medya alanında faaliyet göstermelerinin karlı bir iş olmasının yanı sıra insanların yaşam tarzlarını etkileyip değiştirebilecek ve dolayısıyla elinde bulundurduğu sektörleri canlı tutarak daha karlı hale getirecek bir silaha sahip olmasından ileri gelmektedir. Küresel güçlerin bu aşamada kendi içindeki döngüyü sağlayabilecek bir hamle yaptıkları da ortadadır. Medya işletmelerinin sahiplik yapıları, küresel güçlerin bu alana yatırım yapmaya başlamaları ile birlikte oldukça yoğun bir şekilde tartışılmıştır.

Küresel güçlerin yakın bir geçmişte geleneksel medyanın her alanında yatırım faaliyetinde bulunması ve kısa sürede büyük ekonomik güçleri ile sektöre hakim olmaları, siyasi açıdan da ülkelerin yönetiminde söz sahibi olmalarına neden olmuştur. Medya patronları, sahip oldukları kamuoyu oluşturma gücünü etkin şekilde kullandıklarında, her anlamda büyümüş- 
lerdir. Bu durum, yeni medya araçlarının yaygınlaşmaya başlamasına kadar yoğun bir şekilde devam etmiştir. Yeni medyanın geleneksel medyadan en büyük farkı, içerik üretiminin geniş kitlelere yayılmış olmasıdır.

Yeni medya araçlarının sahiplik yapıları geleneksel medyadan oldukça farklıdır. Özellikle sosyal medya uygulamalarının kısa sürede yaygınlaşması ve kullanıcı sayılarının ciddi oranda artması, herkesin içerik üretebildiği bu ortamın önemli bir kitle iletişim alanı haline gelmesine neden olmuştur. Bu süreç oldukça kısa bir sürede gerçekleştiği için tekelleşme gibi bir durum söz konusu olamamıştır. Yeni medya düzenine dünyanın kısa sürede adapte olması, geleneksel medyanın da yeni medyada etkin bir rol üstlenmesi ile birlikte medya araçları dönüşüme başlamıştır.

Son yıllarda yaşanan" Arap Baharı" ve "Gezi Parkı Eylemleri" gibi birçok toplumsal harekette medyanın önemli bir rolü olmuştur. Geleneksel medya her ne kadar bu konuda otoriter medya görünümünde hareket etse de yeni medya, bu konuda büyük bir aşama kat etmiştir. Toplumsal olaylarda yeni medyanın etkisini gören küresel şirketler ve devletler, bu konuda kendisini yeniden konumlandırma gereği hissetmiş̧tir.

Medya ve reklamclık alanında yaşanan bu olayların odağında şüphesiz ekonomik kaygılar ön plandadır. Küreselleşmenin tek tip toplum hedefi ile çıktığı yolda oldukça başarılı olduğu görülmektedir. Günümüzde insanların yaşam tarzlarının birbirine benzemesi, bir tüketim toplumu yaratılması ve borçlu bir toplumun oluşmasının en büyük silahşor, kuşkusuz medyadır. Medya okuryazarlığının ders olarak okutulduğu günümüzde, küreselleşme konusu bu derslerin odağında yer almaktadır. Küresel güçler hedeflerini gerçekleştirebilmek adına gereken her şeyi yapacaktır. Küresel bir toplumun oluşması, küresel ekonominin sağlam bir şekilde ayakta durması ve küresel şirketlerin daha da büyümesi için geniş kitlelerin şekillendirilmesi en önemli husustur. Küresel güçlerin, geçmişte olduğu gibi gelecekte de bunun için medya araçlarını kullanacağı görülmektedir. Yeni medya araçlarının da hedef kitle ayrımında kolaylıklar sağlaması, küresel güçlerin son yıllarda odaklandığı konuların başında gelmektedir.

Sosyolojik ve psikolojik çalışmaları da kullanan küreselleşme, her dönem farklı bir sosyal etki ile kendini göstermektedir. Son yıllarda gösteriş tüketimi ve züppe etkisi adı verilen bazı tüketim alışkanlıkları ortaya çımıştır. Özellikle gelişmemiş ve gelişmekte olan ülkelerde daha sık görülen bu tüketim alışkanlıkları, medya araçları ile insanlara empoze edilmektedir. 
Gösteriş tüketiminde düşük gelirli insanların çevrelerine durumlarının daha iyi göstermek amacıyla sahip oldukları imkanların üstünde harcama yapmaktadır. Züppe etkisinde ise yüksek gelirli insanların tüketim alışkanlıklarının düşük gelirlilerin taleplerinin tersi yönünde hareket etmesidir. Bu durumda hem düşük gelirli hem de yüksek gelirli insanların tüketim alışkanlıkları ile ilgili küresel güçlerin farklı senaryolar sergilediği görülmektedir. Küreselleşmenin hem düşük gelirli hem de yüksek gelirli insanlara ulaşabileceği en rahat yol ise medya araçlarıdır. Bu bağlamda küreselleşme, toplumun her katmanında var olmak istemektedir ve bunun için kullandığ tetikçi de şüphesiz medya araçlarıdır. 


\title{
EXTENDED ABSTRACT
}

\section{Triggers Of Globalization: Media}

\author{
Volkan Yavuz \\ Hacı Bayram Veli University
}

With the increase in industrialization in the recent period, there has been a transition from the production society to the consumption society. At the point we have reached, large production facilities have been established with the help of technology, and mass production has become a method used by almost every industry. This increase in production caused the necessity to produce in direct proportion to consumption. This perspective was changed by the producers after a while and by increasing the consumption, it was evolved towards making more production and making the producers gain more. The promotion of products has been identified as the most effective way to increase consumption. In this process, advertising has become an important tool. Starting with the product-information format at the end of the 19th century, the advertising structures continued with the product-image period, the personalization format period and the lifestyle format period. In the last period called the lifestyle format, a format has been imposed on people through various communication tools, and people who live in this format are entering the hegemony of globalization. It is very difficult to avoid this in the age we live and in the society we live in.

Increasing the value of the media has increased the quality of communication tools, communication devices reaching almost every part of the world and being the most important channels of the advertising sector and high revenues. The media sector also appears to be a major employment area. The print media emerged after the invention of the printing press and has remained the most important mass media in the world for several centuries. Radio and television entered the lives of people, respectively, after the print media, the world's largest mass media until the 20th century. Television broadcasting has been popular with people in a short time. Since television broadcasting is done through waves, systems transferring these television images from the center to other regions have been established. 
These systems later extended to satellite technologies and become today. Technologies used in television broadcasting have been improving day by day and television viewing rates have increased. This process was also the period when television was considered as an advertising medium. The advertising industry has always chosen the easiest way to reach its target audience. Television broadcasting has also become the most valuable medium of the advertising industry because it appeals to large audiences. Today, it still remains the most valuable advertising medium.

New media tools, which have emerged with the widespread use of computer and internet technologies, have increased the number of users in recent years and have become the second place after television in advertising investments. New media tools offer huge advantages for advertisers. One of these advantages is that it can easily reach the target audience and target individuals.

The fact that people are constantly interacting with media means creates a great advantage for the advertising industry. Thanks to the advertising industry that uses this situation, consumption cultures are shaped on a global scale. Creating a need for people is the basis of the consumption culture. In fact, the fact that people buy the products they don't need clearly shows how the consumption culture is shaped. There were quite different cultures around the world when communication tools were not common. In every society, people's daily lives and needs were determined. These needs varied greatly from society to society. With the development of communication and transportation technologies, local features started to decrease and global values began to develop gradually. It is one of the clearest facts of our day, where the daily lives of people in quite different geographies are increasingly similar.

In the work of McLuhan, he talked about the concept of "Global Village" in the middle of the last century. Today, everybody talks about how small the Earth is, and it can be easily spoken to people in any geography, instantly and visually. This situation ensures that people's lives and needs are similar. The concept of globalization comes into play at this stage. Creating a common global culture in the world and changing the consumption habits of people in this global culture are the main targets of globalization.

Large capital groups called global powers are constantly working to protect these powers and create slaves for themselves. That's why one of the 
most important subjects of communication science is globalization. Globalization consists of an abstract concept. Those who serve this abstract concept do not even have an idea of what they serve. It is unthinkable that global powers are independent of states. States interact with each other in line with their relations. Large states use this business as a great advantage especially against small countries. Since the big states also have effective communication ways, they successfully carry out activities that will benefit them.

It is observed that the global powers invested in the media especially at this stage. These global powers can easily realize their goals through the media. Global powers can change the buying tendency of people through advertisements in media, as well as creating a life model for people with other contents. As long as this cycle continues, people under the influence of global powers earn money by working and spend it through the life model determined by global powers.

The determinants of the global culture are constantly in new pursuits. Even though there are some changes in practice, flashy lives are shown to low-income people due to the human fit and impose an idea that they may or may not be like them. It also offers alternatives to high-income people who can make a difference from low-income people. Globalization, which applies different strategies according to each income group, aims to be in every segment of the society. Media is undoubtedly the most effective tool used by globalization in doing so.

\section{Kaynakça / References}

Adaklı, G. (2001). Yayıncılık alanında mülkiyet ve kontrol. (Der. B. Kejanlıŏlu, S. Çelenk ve G. Adaklı). Medya Politikaları, Türkiye'de Televizyon Yayıncllı̆ı̆ını Dinamikleri İçinde (s.145-203). Ankara: İmge Yayınevi.

Aydoğan, F. (2009). Tüketim kültürünün gölgesinde kentler. Marmara Üniversitesi Iİ BF Dergisi, 27(2), 203-215.

Boratav, K. (2000). Emperyalizm mi? küreselleşme mi?. (Der. E. Ahmet Tonak). Küreselleşme: Emperyalizm, Yerelcilik, İş̧i Sınıfı. Ankara: İmge Kitabevi

Dağtaş, B. (2003). Reklamı okumak. Ankara: Ütopya Yayınevi.

Dağtaş B. (2009). Reklam kültür toplum. Ankara: Ütopya Yayınevi. 
Dağtaş, B. ve Dağtaş E. (2009). Tüketim kültürü, yaşam tarzları, boş zamanlar ve medya üzerine bir literatür taraması. (Der. B. Dağtaş ve E. Dağtaş) Medya Tüketim Kültürü ve Yaşam Tarzlar Türkiye Medyasından Örüntüler içinde (s.27-75). Ankara: Ütopya Yayınevi:

Giddens, A. (1998). Modernliğin sonuçları. (Çev. E. Kuşdil). İstanbul: Ayrıntı Yayınları.

Giddens, A. (2010). Modernite ve bireysel-kimlik geç modern çă̆da benlik ve toplum. (1. Bask1), İstanbul: Say Yayınları

Gökçe, O. (1993). İletişim bilimine giriş. Ankara: Turhan Kitabevi.

Held, D. ve McGrew A. (2008). Küresel dönüşümler büyük küreselleşme tartışması. Ankara: Phoenix Yayınevi

İçli, G. (2001). Küreselleşme ve kültür. Cumhuriyet Üniversitesi Sosyal Bilimler Dergisi, 25(2), 163-172.

Kim, Y. Y. ve Bhawuk, D.P.S. (2008). Globalization and diversity: contributions from intercultural research. International Journal of Intercultural Relations.

McChesney, Robert W. ve Dan S. (2003). the political economy of international communications: Foundations for the emerging global debate about media ownership and regulation. Genava. United Nations Research Instute for Social Development.

Kutlu, E. (1998). Dünya ekonomisi. Eskişehir:Anadolu Üniversitesi Basımevi.

Okuroğlu, S. (2012). Türkiye'de medya tekelleşmesinin ekonomisi ve medya siyasaları. (Ed. E. Dağtaş). Küreselleşme, Medya, Toplum. Ankara: BirGün Kitap

Parlak, Z. (1999). Yeniden yapılanma ve post-fordist paradigmalar. Bilgi Sosyal Bilgiler Dergisi, 1(1), 83-102.

Reklamcılar Derneği (2018). Türkiye'de tahmini medya ve reklam yatırımları: 2018 yıl sonu raporu. 07.09.2019 tarihinde http://rd.Org.Tr/Assets/Uploads/Bf6ab5b5-0d86-4bc3-92a7Da47c165cb61.Pdf adresinden erişilmiştir.

Setzer, M. (1997). Ekonomik küreselleşme: Küreselleşmenin ekonomi ve teknoloji üzerindeki etkileri. Ankara: SODEV Yayınları.

Steger, Manfred B. (2006). Küreselleşme. Ankara: Dost Kitabevi.

Tutal, N. (2006). Küreselleşme iletişim kültürlerarasılık. (1. Baskı) İstanbul: Kırmızı Yayınları 
Ratem (2013) Türkiye Radyo ve Televizyon Yayıncları Meslek Birliği sektör raporu. 28.11.2019 tarihinde $\underline{\text { https://cb1c88d0-6fa4-44ce-be45- }}$ a0f84be05556.filesusr.com/ugd/0349e3 603840f8555a4a9aa8d6cd4946 bac7c1.pdf adresinden erişilmiştir.

Yağlı, S. (2006). Gündelik hayatımızda akıl tutulması: Medya uygulamalarında tüketim ideolojisinin izlerini sürmek. (Der. S. İçin Akçalı) Gündelik Hayat ve Medya: Tüketim Kültürü Perspektifinden Okumalar. İçinde (s.5-42). Ankara: Babil Yayınevi.

\section{Kaynakça Bilgisi / Citation Information}

Yavuz, V. (2020). Küreselleşmenin tetikçisi: Medya. OPUS-Uluslararası Toplum Araştırmaları Dergisi, 15(22), 1460-1480. DOI: 10.26466/opus.647114 